\title{
Algo sobre la biografía de Horacio y sus contradicciones
}

\author{
Bartolomé Segura Ramos
}

La figura de los escritores se oculta detrás de su obra, apenas queda otra cosa que no sea la obra misma, donde se expresa por lo demás lo que el poeta piensa, cree y siente. ¿Qué más podemos pedir? Seguir la lectura de una obra es oír a un hombre desaparecido, perdido en los lizos del tiempo y de la historia, hablando de las cosas que pensó o sintió, de modo que el estilo de cada cual nos revela quién era cada cual. Por tanto, aunque no tengamos noticia alguna de este o aquel autor, podemos imaginamos lo que era, si es que tenemos algún interés en saber cómo era, a través de las líneas que nos ha dejado escritas, pues, quiérase o no, y a pesar de que cuando el escritor escribe lo hace dentro de una tradición, de un género, que coarta la manifestación de su propia manera de ser, siempre se escapa lo suficiente, si es que tenemos interés, repito, en saber cómo era, para averiguarlo. Y aunque afirmamos que lo importante de un autor es su obra, todos caemos una y otra vez en el ferviente deseo de conocer la cara que se oculta detrás de la obra. Sólo que sabido es que después de la lectura nos creamos una imagen del autor que no tiene por qué corresponderse con la realidad, con la verdadera imagen, si es que esto es posible; y sobre todo, inevitablemente, la imagen que emerge nos decepciona porque irremediablemente hemos idealizado al autor, lo hemos visto a través de las palabras, y estas son siempre abstractas, generales, irreales. Detrás de las palabras empieza la vida real, el hombre material, condicionado por el espacio y el tiempo, por el frío y el calor y las necesidades ineludibles: entonces las palabras se revelan huecas, carentes de significado, se revelan creadoras de ilusión, y como tal sólo tienen sentido en el mundo de la fantasía que hemos forjado.

En elmeticuloso estudio y análisis a que se somete a los escritores que habitualmente nos ocupa, sea Virgilio, Cervantes o Shakespeare, tratamos de indagar la razón de cada una de sus palabras, de sus frases, de sus alusiones, como si de la amada se tratase, y con frecuencia les exigimos demasiado, y sobre todo, llevados de la inevitable simplicidad a que tendemos para entender lo que miramos, aspiramos a hallar en ellos una absoluta cohesión y armonía, y nos sorprendemos ingratamente cuando descubrimos que en ellos también anidan las contradicciones. Los queremos puros, grandes, por encima del bien 
y del mal. Pero acontece que poseen un cuerpo de mortal, acontece que nacieron también en circunstancias más o menos similares a las de los demás mortales, y de esta manera, Horacio, por poner un ejemplo, nació en Venusia, entre la Apulia y la Lucania como él nos dice (Sátiras II 1, 34-39): Sequor (sc. Lucilium), Lucanus an Apulus anceps: / nam Venusinus at finem sub utrumque colonus, I missus ad hoc, pulsis, uetus est ut fama, Sabellis, / quo ne per uacuum Romano incurreret hostis, / siue quod Apula gens seu quod Lucania bellum / incuteret uiolenta: «Sigo a éste (Lucilio), sins saber si soy lucano o pullés, pues el colono venusino ara en el límite de ambos, enviado como fue, según se sabe de antiguo, para que tras ser expulsados los sabelios el enemigo no se enfrentara a los romanos en tierra de nadie, bien que hiciese la guerra el pueblo pullés o la Lucania violenta», un día de otoño del año 65 a. E., y era bajo de estatura (breuis) y tenía la vista mala (Sátiras I 5, 30-31: Hic oculis ego nigra meis collyria lippus / illinere: «Aquí unté mis ojos de colirio negro porque tenía mal la vista»). De modo que detrás de sus sátiras y epodos emerge un hombrecito pequeño, rechoncho y con tendencia a tenermal la vista, tal vez. Pues este hombre era hijo de un coactor o «recaudador de impuestos», que era además un liberto, un esclavo liberado en su día (Sátiras I 6,6: ut me libertino patre natum: «Como yo, hijo de un padre liberto»). ¿Y qué podía hacer un hijo de liberto en la Roma de Augusto, en la Roma que salía de las guerras civiles? Y no olvidemos que Horacio además combatió con los republicanos y con ellos cayó derrotado en la batalla de Filipos del año 42, cuando (Odas II 7, 11-12): fracta uirtus, et minaces / turpe solum tetigere mento,: «El valor quedó quebrantado, y los fanfarrones mordieron el polvo vergonzosamente». Pues resulta que el pobre liberto que fue el padre de Horacio no se conformaba con dar a su hijo la educación mínima que podía darle en Venusia entregado elniño a los cuidados de Orbilio, «el pegón» (Epístolas II 1,70-71: meminiquaeplagosum mihi paruo / Orbilium dictare: «Recuerdo los poemas que me dictaba de chico Orbilio, el pegón». No quiso su padre in Flaui ludum me mittere, magni / quo pueri magnis e centurionibus orti, / laeuo suspensi loculos tabulamque lacerto, / ibant octonos referentes Idibus aeris: «Enviarme a la escuela de Flavio, donde iban los niños importantes de importantes centuriones con la bolsa y la tabla colgadas del brazo izquierdo, llevándole cada Idus los ocho sestercios» (Sátiras I 6, 72-75). En vez de ello, el padre lo envió a Roma (ibídem, 76-78): sedpuerum est ausus Roman portare, docendum/artis quas doceat quiuis eques atque senator / semet prognatos : «Osó enviar al niño a Roma, para enseñarle los estudios que los caballeros y senadores enseñaban a sus propios hijos», manifestando Horacio una estima excepcional por su padre, y agradeciéndole a renglón seguido, en la misma sátira, los sólidos principios morales que le enseñó. Pues bien, cualquier lector estaría tentado de llamar contradictorio a Horacio por el hecho de que por un lado se jacta de haber recibido enseñanza tan sólida, y por otra parte haya escrito odas ligeras y escabrosas, por ejemplo. De modo que una primera contradicción sería ésta. Primero, enla misma sátira, verso 82, ss., afirma Horacio: Quid multa? Pudicum, qui primus uirtutis honos, seruauit ab omni / non solum facto, uerum opprobrio quoque turpi: «Para abreviar, me guardó con pudor, que es el primer honor de la virtud, libre de toda acción vergonzosa y también de todo oprobio vergonzante». Frente a esta pretensión el poeta escribe tantas odas eróticas que algunos pueden pensar contradicen estos principios tan sanos y por él tan loados. 
De la misma manera, ¿cómo se concilia el Carmen Saeculare, que entona el panegírico de Roma eterna, cómo conciliar las seis Odas llamadas romanas (Odas III 16) con su filosofía epicúrea, tan ajena aparentemente a una sumisión política y formal como esas odas hacen suponer? Pues más abajo, en la misma sátira, el poeta describe la vida de un hombre público, los actos sociales que debe realizar y que a él le resultan insufribles, como tener que hacer más fortuna, tener que saludar a mucha gente, tener que ir acompañado siempre de una par de personas, alquilar mozos, apacentar caballos y alquilar carrozas (100-104). Claro que por mucho que se diga respecto a la honestidad con que Horacio escribió los siete poemas aludidos, es evidente que el Carmen Saeculare, por ejemplo, es bastante pobre de inspiración, lo que revela que no le hizo gracia alguna a su autor, y en cuanto a las famosas odas romanas, habría mucho que hablar. Pues en primer término, no hay que olvidar que si Horacio exalta ahí los principios de la tradición romana, hasta cierto punto ello está en la línea de esos versos de las sátiras en que el poeta elogia a su padre y le agradece la enseñanza que le dio. De modo que por ese lado Horacio estaba dentro de la tradición común a todos los poetas romanos, casi sin excepción, por cuanto todos cumplían con el tópico de exaltar el pasado y censurar acremente el presente. Ahora bien, ¿cómo conciliar tan altas pretensiones con el hecho histórico de que Horacio, que habla que «por culpa de los padres son menos los jóvenes» (Odas I 2324: uitio parentum/rara iuuentas, él en cambio permaneciese soltero y cantase principalmente el amor sin trabas, el amor fácil de esclavas y libertas? Estas son algunas de las contradicciones, las más groseras y de bulto que algunos observan en el poeta de Venusia; pero hay otras más, que son más sutiles, y que pueden estudiarse dentro de la misma perspectiva, a saber, que tales contradicciones o no son tales, o si lo son, ¿qué importancia tienen? En primer término, hay que tener presente que cuando un autor, o en términos generales, una persona cualquiera, escribe o habla, es dentro del contexto en que escribe o habla como dice lo que dice o escribe lo que escribe de manera que en esta sátira a Mecenas (I6) Horacio habla de su padre, porque está hablando de la nobleza de Mecenas, y de que pese a ser tal el ministro de Augusto ampara a quienes no tienen nobleza familiar, porque Mecenas empezó a valorar otros méritos distintos a los familiares, como los méritos y valía personales (en lo que el propio Augusto tenía igualmente interés en promocionar a los demás, pues él mismo era de origen ecuestre y provincial), y es ese contexto en que viene a cuento que Horacio hable de sí mismo y manifieste cómo la formación personal tiene más valor que los cargos públicos y que la nobleza de la sangre, en muchos casos. En esa misma línea tiene que ponderar a su padre, gracias al cual recibió una esmerada educación que más tarde le permitiría escribir y ganarse el aprecio del todopoderoso ministro de Augusto. ¿Qué tiene que ver el contexto aquí bosquejado con unas odas en las que Horacio, poeta anacreóntico, pindárico, etc., pretende reproducir en latín la poesía griega de los griegos, odas en las que aborda temas variados, comunes y recurrentes en la poesía griega, cuyo modelo tiene continuamente presente y en la que, en efecto, eran esos los temas que estaban a la orden del día? Ya dijimos arriba que no sabemos habitualmente cómo ha sido un escritor, porque los poetas escriben dentro de una tradición y de un género, se atienen a sus leyes y no hablan normalmente de sí mismos. Y esto ocurre todavía menos entre los autores de la Antigüedad, más apegados a los géneros y a sus convenciones, de tal 
modo que en la épica, por ejemplo, es prácticamente imposible que un poeta hable de sí mismo, porque ello está excluido absolutamente por las leyes del género, pero tampoco los demás géneros se prestaban a confidencias personales, exceptoprecisamente, en las sátiras o epístolas, como las de Horacio, donde las referencias autobiográficas abundan más que en ninguna otra obra de poeta romano alguno. Así que precisamente de Horacio conocemos más que de los demás poetas latinos, pues Virgilio no podía referirse a sí mismo en la Eneida, que es épica, y poco aludió a su propia persona en las Bucólicas, ya que hay que leer entre líneas para descubrir que en la Égloga I hay referencias autobiográficas encubiertas en los personajes Títiro y Melibeo, y en las Geográficas hay algún pasaje en que el poeta alude a sus gustos literarios más bien, con los que resulta que es bien poco lo que conocemos de él por él. Pero afortunadamente Horacio es otra cosa, y es por eso, porque sabemos de su persona, por lo que es más tentadora la idea de sorprenderle en contradicción consigo mismo, ya que si no hubiese hablado de sí no habría lugar a esta comparación entre sus palabras, sus pensamientos escritos y transmitidos y lo que realmente él era.

Tenemos dos respuestas a esas supuestas contradicciones, la primera de las cuales ya la señalamos al principio, y es de carácter bastante general y abstracto, y consiste en la necesaria contraposición entre palabras y vida real y material del autor; la otra razón acabamos de pergeñarla más arriba, cuando hemos afirmado que los contextos son distintos. Pero además, estamos insinuando que existe todavía otra razón que da cuenta de estas contradicciones, que en realidad, en la mayoría de los casos, no son sino aparentes, y es que el género impone sus condiciones y el poeta dice sentir y pensar cosas que tal vez no piensa ni siente. Mas cuando leemos y observamos que en las Odas se repiten las situaciones, y recurren los pensamientos y sentimientos, entonces deducimos que es verdad, que esos son los pensamientos y sentimientos del poeta: de modo que ya sabemos que era soltero y amante de cualquier amor que le saliese al paso, contra las leyes y la política de Augusto que pretendían primar a los casados y la natalidad, y este poeta propagandístico incumple abiertamente los preceptos de su amo y se pone a hacer el amor y a cantarlo de la forma más lozana y placentera que imaginar quepa. ¿Qué decir entonces de este individuo, procaz y guasón, voluptuoso y anárquico? Suponiendo que las leyes del género no den cuenta cabal de estas contradicciones (y no parece que debamos dudar de lo que leemos respecto al pensar y sentir de este poeta) debemos pasar adelante y volver a generalizar, porque sólo de una manera abstracta se dan las contradicciones. Pues esto es lo que ocurre, que sólo cuando comparamos sus asertos morales (pues Horacio, como todos los poetas de la Antigüedad, se preocupa fundamentalmente de los principios morales y éticos), con lo que desea y siente, hallamos esta contradicción. Mas cuando así juzgamos y actuamos estamos comportándonos de forma manifiestamente maniquea: las palabras son metas, los actos son la materia real de la vida: ¿por qué han de corresponder los actos reales, inamovibles, a las metas, que como tales no existen ni pueden existir? Ello para no hablar del fariseísmo que implica decir que Horacio es contradictorio porque en una parte aconseja que la gente se case y tenga hijos, que se atenga a los mores maiorum (como hacían todos los escritores en sus prédicas morales), que los jóvenes romanos amen la patria y la defiendan, mientras él permanece soltero, ama esencialmente su independencia (Sátiras I6, 111 ss.: quacumque 
libido est, / incedo solus; percontor quanti holus ac far; I fallac cem Circum uespertinumque pererro / saepe Forum; adsisto diuinis; inde domum me / ad porri et ciceris refero laganique catinum; / cena ministratur... 119 ss.: deinde eo dormitum, non sollicitus mihi quod cras / surgendum sit mane... 122: ad quartam iaceo; post hanc uagor; aut ego lecto / aut scripto quod me tacitum iuuet unguor oliuo: «Por dondequiera que me venga en ganas paseo a solas; pregunto lo que vale la verdura o el trigo; deambulo muchas veces por el Circo engañoso y por el Foro, al caer la tarde; me paro delante de los adivinos, y luego me vuelvo a casa, al plato de puerros y chícharos, y a mis buñuelos. Me sirven la cena... Luego, me voy a dormir, sin la preocupación de tener que levantarme temprano mañana. Me quedo en la cama hasta las once, y después paseo, o tras leer o escribir lo que satisface a mí solo, me unto de aceite», ama su vino y sus amores, y ha abandonado su escudo en la batalla de Filipos (Odas II 7, 10: relicta non bene parmula). Una persona puede obras asi y afirmar y creer lo contrario, sin que por ello debamos rasgarnos las vestiduras.

Así que esta es la vida de Horacio, y la descripción recogida arriba resume sus pretensiones, como todo el mundo sabe. Es difícil que tengamos de otro poeta una relación tan minuciosa, tan a la hora, de la propia vida (sí la tenemos de Cicerón, porque sus cartas nos ilustran sobre muchas menudencias de su vida; aunque no hemos de creer que el hecho de escribir cartas implica necesariamente una mayor información, pues ahí tenemos a nuestro Séneca que escribió sus ciento y pico cartas a Lucilio y apenas nos dio datos precisos sobre su vida; sólo que la correspondencia de Cicerón es de naturaleza diferente a Séneca: aquella sabemos que fue vida y real; la de éste dudamos de que lo fuese). Y tengamos también presente la Sátira I 5, en que el poeta describe el viaje a Brindis en la primavera, probablemente, del 38. La formación que Horacio nos ha confesado debe a su padre se resume en estos pocos versos de Sátira I4, 134-137: Rectius hoc est: / hocfaciens uiuam melius: sic dulcis amicis / occurram; hoc quidem non belle; numquid ego illi / imprudens olim faciam simile?: "Así está bien; obrando así viviré mejor; así me mostraré dulce a los amigos; esto en cambio no está bien. ¿Le voy a hacer yo algo semejante a aquél un día, sin darme cuenta?». Aquí Horacio nos descubre un corazón de oro. ¿Era así? Posiblemente, sí. Pese a la cólera de la que era víctima frecuente (Odas I 16, 22-26): me quoque pectoris / temptauit in dulci iuuenta / feruor et in celeris iambos / misit furentem: nunc ego mitibus / mutare quaero tristia: «A mí también me tentó en la dulce juventud el fervor del pecho, y me lanzó enfurecido a los yambos raudos; ahora busco yo trocar la amargura por la amabilidad», y algo más arriba, en la misma Oda, verso 9, había hablado de las tristes irae. En cualquier caso, y respecto a esas contradicciones que se advierten desde el instante que conocemos mucho de la vida real del poeta (cotidiana o normal, diríamos mejor), he aquí el testimonio que él nos ofrece y que demuestra bien a las claras que conocía a la perfección estas contradicciones que los modernos ven en él y que expresa por boca de su esclavo Davo en Sátiras II 7, 22 ss.: Laudas / fortunam et mores antiquae plebis, et idem / si quis ad illa deus subito te agat, usque recuses, I aut quia non sentis quod clamas rectius esse, I aut quia non firmus rectum defendis, et haeres / nequiquam caeno cupiens euellere plantam. / Romae rus optas, absentem rusticus urbem / tollis ad astra leuis...: «Alabas la suerte y las costumbres de la gente antigua y, no obstante, si la divinidad te condujese de repente a 
aquellos, al instante rehusarías, bien porque no sientes que sea mejor lo que proclamas, o bien porque defiendes lo bueno sin firmeza y te atascas en el cieno ansioso por sacar el pie en vano. En Roma anhelas el campo, y cuando estás en él, voluble como eres, ensalzas la ciudad hasta los astros...». 